\title{
In vitro and in vivo antitrypanosomal activities of three peptide antibiotics: leucinostatin A and B, alamethicin I and tsushimycin
}

\author{
Aki Ishiyama, Kazuhiko Otoguro, Masahito Iwatsuki, Miyuki Namatame, Aki Nishihara, Kenichi Nonaka, \\ Yuta Kinoshita, Yoko Takahashi, Rokuro Masuma, Kazuro Shiomi, Haruki Yamada and Satoshi Ōmura \\ In the course of our screening for antitrypanosomal compounds from soil microorganisms, as well as from the antibiotics \\ library of the Kitasato Institute for Life Sciences, we found three peptide antibiotics, leucinostatin (A and B), alamethicin I \\ and tsushimycin, which exhibited potent or moderate antitrypanosomal activity. We report here the in vitro and in vivo \\ antitrypanosomal properties and cytotoxicities of leucinostatin A and B, alamethicin I and tsushimycin compared with suramin. \\ We also discuss their possible mode of action. This is the first report of in vitro and in vivo trypanocidal activity of leucinostatin \\ $A$ and $B$, alamethicin I and tsushimycin.
}

The Journal of Antibiotics (2009) 62, 303-308; doi:10.1038/ja.2009.32; published online 1 May 2009

Keywords: antitrypanosomal peptide antibiotics; HAT; in vitro; in vivo; screening; T. b. rhodesiense; Trypanosoma brucei brucei

\section{INTRODUCTION}

Human African trypanosomiasis (HAT), also known as Sleeping Sickness, is recognized as one of the world's most neglected diseases and causes significant and widespread mortality and morbidity in subSaharan Africa. Two sub-species of trypanosomes, Trypanosoma brucei rhodesiense (found in eastern and southern Africa) and T. b. gambiense (found in west and central Africa) infect humans and wild animals, as well as domestic animals, such as pigs and dogs. Another sub-species, T. $b$. brucei, infect cattle, causing Nagana disease, which devastates livestock production and causes massive economic losses.

The trypanosome parasites are transmitted through the bite of blood-sucking tsetse flies (Glossina spp.). Transmission of T. $b$. gambiense is mostly human-to-human, whereas wild animals and humans both act as reservoir hosts for T. $b$. rhodesiense. During a bite from an infected tsetse, parasites are introduced into the bloodstream in which they multiply and then pass into the lymph system. This represents the early stage of HAT, during which the patient may suffer from fever, headaches, joint pains or itchiness. The second, or late, stage is more critical, because of parasites crossing the bloodbrain barrier and invading the central nervous system. This results in loss of sensation, neuropathy, sleeping disorder, coma and ultimately death. T. $b$. rhodesiense infection is acute, lasting from a few weeks to several months, whereas T. b. gambiense infection is chronic, persisting for several years, during which times patients may be asymptomatic. In the absence of effective diagnosis and treatment, both forms cause death in humans, the former much more rapidly.
Accurate statistics for HAT are lacking, as many cases are not reported. The World Health Organization estimated that, in 2000, the disease affected some 300000 Africans, a figure far in excess of the 27000 cases reportedly diagnosed and treated that year. By 2005, surveillance had been reinforced, case reporting improved and was held to be more accurate, with the number of new cases actually reported falling substantially. Between 1998 and 2004, the figure for cases of both forms of the disease combined was estimated to have fallen from 37991 to 17616 , reducing further to 10769 in 2007. The estimated number of actual cases of infection is currently $50000-70000 .^{1,2}$

Currently, the drugs pentamidine and suramin are used in the early stage of T. $b$. gambiense and T. $b$. rhodesiense infections, and melarsoprol is used in the late stage, whereas eflornithine is only used in the late stage of $T . b$. gambiense infections. These drugs are old and highly unsatisfactory, as they cannot be given orally and can be dangerous because of their severe toxicity. Melarsoprol is particularly hazardous, with $5-10 \%$ of patients dying because of toxic side effects. ${ }^{3}$ Suramin, discovered in 1921, which is still commonly used for treatment of early-stage $T . \quad b$. rhodesiense, provokes undesirable side effects in the urinary tract and causes major allergic reactions. Pentamidine, routinely used for treatment of early-stage Gambiense sleeping sickness was introduced in 1941 and, despite a few undesirable effects, it is generally well tolerated by patients. However, drug resistance in trypanosomes is increasing and treatment failures are becoming more common., ${ }^{4,5}$ Therefore, there is an urgent need for new antitrypanosomal drugs

Research Center for Tropical Diseases, Center for Basic Research, Kitasato Institute for Life Sciences and Graduate School of Infectious Control Sciences, Kitasato University, Tokyo, Japan

Correspondence: Dr K Otoguro, Research Center for Tropical Diseases, Center for Basic Research, Kitasato Institute for Life Sciences and Graduate School of Infectious Control Sciences, Kitasato University, 5-9-1 Shirokane, Minato-ku, Tokyo 108-8641, Japan.

E-mail: otoguro@lisci.kitasato-u.ac.jp

Received 13 March 2009; revised 30 March 2009; accepted 1 April 2009; published online 1 May 2009 
that are more effective and safer, especially those that have novel structures and mechanisms of action.

During our program to screen soil microorganisms and compounds from the antibiotic library of the Kitasato Institute for Life Sciences to discover antitrypanosomal substances, we earlier reported that various microbial metabolites exhibit potent antitrypanosomal properties. ${ }^{6,7}$ We have discovered a further three peptide antibiotics, leucinostatin A and B (produced by soil fungi, Paecilomyces sp.) and alamethicin I and tsushimycin (from the antibiotic library) (Figure 1), which show potent or moderate antitrypanosomal properties. We report here the in vitro and in vivo antitrypanosomal activities and cytotoxicities of these peptide antibiotics, as compared with the widely used trypanocidal drug suramin.

Leucinostatins, isolated from cultured broth of Paecilomyces spp., were discovered to possess antitrypanosomal properties, although the structure-activity relationship of antitrypanosomal compounds remains unknown. ${ }^{8}$

The present observations are the first reports of in vitro and in vivo antitrypanosomal activities of leucinostatin A and B, alamethicin I and tsushimycin.

\section{MATERIALS AND METHODS}

\section{Chemicals}

Leucinostatin A and B were isolated from a culture broth of Paecilomyces sp., FKI-3045 at the Kitasato Institute for Life Sciences. Alamethicin I and tsushimycin were obtained from the antibiotics library of the Kitasato Institute for Life Sciences.
Suramin was provided by Professor R Brun (Swiss Tropical Institute, Basel, Switzerland). Iscove's modified Dulbecco's medium (with L-glutamine and HEPES, without $\mathrm{NaHCO}_{3}$ ), minimum essential medium (MEM) with Earle's salts, MEM non-essential amino acids solution and penicillin-streptomycin solution were obtained from Gibco Laboratories Life Technologies (Grand Island, NY, USA). Fetal bovine serum was obtained from SigmaAldrich Inc (St Louis, MO, USA) and horse serum was obtained from Gibco Laboratories Life Technologies. Alamar Blue reagent was obtained from Sigma-Aldrich Inc.. Other chemicals were commercially available and all of analytical grade.

\section{Taxonomic studies of FKI-3045}

Fungal strain FKI-3045 was isolated from soil collected in Ishigaki Island, Okinawa, Japan. The micro-morphological characteristics of samples were observed under a Vanox-S AH-2 microscope (Olympus, Tokyo, Japan) and the ITS1 sequence of the strain FKI-3045 was deposited at the DNA Data Bank of Japan, with accession number AB480689. From the results of general characteristics, ${ }^{9}$ the total length of the ITS 1 and BLAST search, ${ }^{10}$ the producing strain FKI-3045 was identified as a strain of Paecilomyces sp.

\section{Fermentation, isolation and identification of leucinostatins}

A loopful of spores of Paecilomyces sp. FKI-3045 was inoculated into $100 \mathrm{ml}$ of seed medium consisting of $2.0 \%$ glucose, $0.2 \%$ yeast extract, $0.5 \%$ Polypepton (Wako Pure Chemical Industries, Osaka, Japan), $0.05 \% \cdot \mathrm{MgSO}_{4} 7 \mathrm{H}_{2} \mathrm{O}, 0.1 \%$ $\mathrm{KH}_{2} \mathrm{PO}_{4}$ and $0.1 \%$ agar (adjusted to $\mathrm{pH} 6.0$ before sterilization) in a $500-\mathrm{ml}$ Erlenmeyer flask. The inoculated tube was incubated in a rotary shaker (210 r.p.m.) at $27^{\circ} \mathrm{C}$ for 3 days. The seed culture $(1 \mathrm{ml})$ was transferred to 500-ml Erlenmeyer flasks (total 93 flasks) containing $100 \mathrm{ml}$ of production medium consisting of $1.0 \%$ glucose, $2.0 \%$ soluble starch, $2.0 \%$ soybean oil,

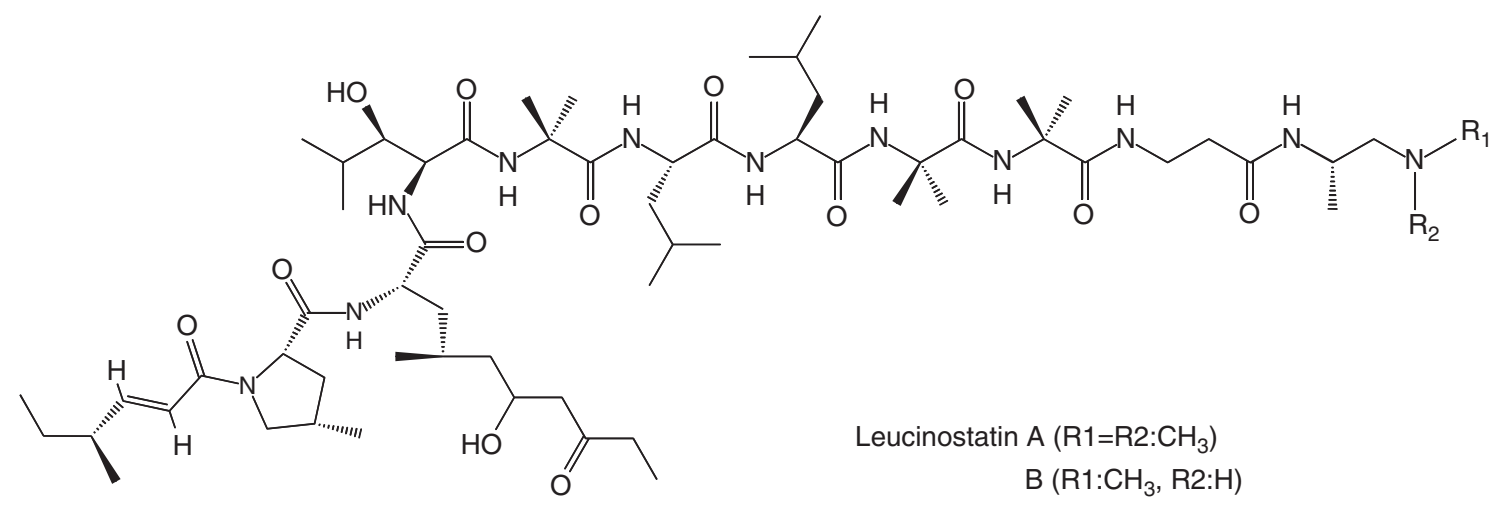

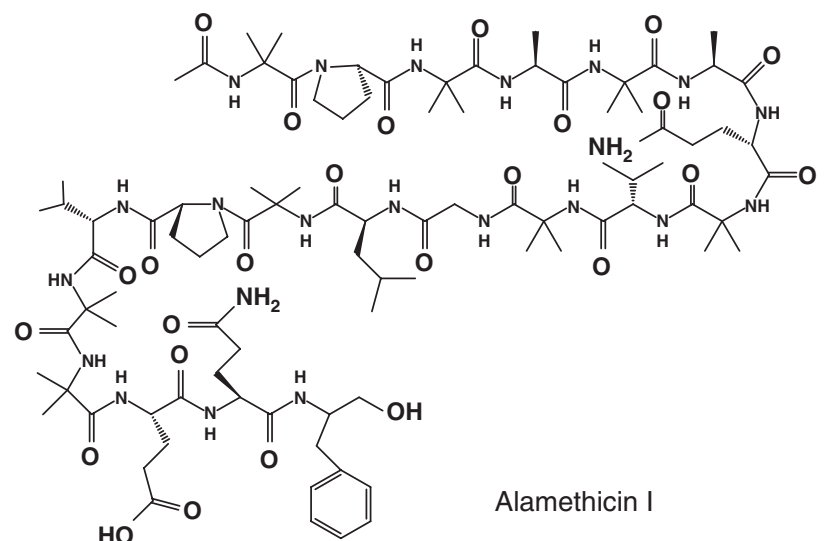

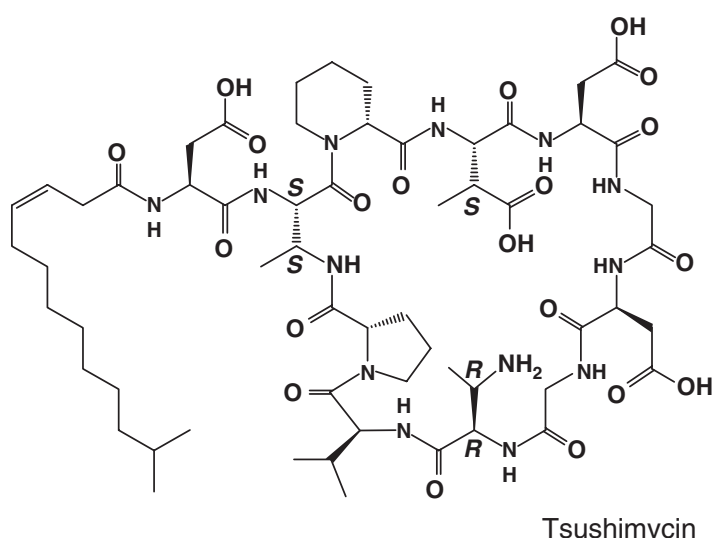

Figure 1 Structures of leucinostatin A and B, alamethicin I and tsushimycin. 
1.0\% Pharmamedia (Traders Protein, Lubbock, TX, USA), 0.5\% meat extract, $0.1 \% \quad \mathrm{MgSO}_{4} \cdot 7 \mathrm{H}_{2} \mathrm{O}, 5.0 \times 10^{-4} \% \mathrm{FeSO}_{4} \cdot 7 \mathrm{H}_{2} \mathrm{O}, 5.0 \times 10^{-4} \% \quad \mathrm{MgCl}_{2} \cdot 4 \mathrm{H}_{2} \mathrm{O}$, $5.0 \times 10^{-4} \% \mathrm{CuSO}_{4} \cdot 5 \mathrm{H}_{2} \mathrm{O}$ and $5.0 \times 10^{-4} \% \mathrm{CoCl}_{2} \cdot 6 \mathrm{H}_{2} \mathrm{O}$ and $0.3 \% \mathrm{CaCO}_{3}$ (adjusted to $\mathrm{pH} 6.0$ before sterilization), and the fermentation was carried out on a rotary shaker ( 210 r.p.m.) at $27^{\circ} \mathrm{C}$ for 3 days, followed by stasis at $27^{\circ} \mathrm{C}$ for 6 days.

The 9-day-old culture broth (9.31) was extracted with $\mathrm{EtOH}$, followed by filtration. The fitrate was extracted with EtOAc. The EtOAc extract (12.1 g) was applied to a Diaion HP20 column $(100 \phi \times 120 \mathrm{~mm}$, Nippon Rensui Co., Tokyo, Japan). After washing with 50 and $60 \%$ acetone aq soln (31 each), the active materials were eluted with $80 \%$ acetone aq soln. The material $(10.2 \mathrm{~g})$ was applied to an octadecylsilyl (ODS) column $(35 \phi \times 200 \mathrm{~mm}$, Senshu Scientific Co., Tokyo, Japan). After washing with 20 and $40 \% \mathrm{CH}_{3} \mathrm{CN} / 0.1 \% \mathrm{HCOOH}$ aq soln $\left(400 \mathrm{ml}\right.$ each), the active materials were eluted with $60 \% \mathrm{CH}_{3} \mathrm{CN} / 0.1 \%$ $\mathrm{HCOOH}$ aq soln. The material $(66.8 \mathrm{mg})$ was purified by HPLC on a Xbridge phenylhexyl column $(10 \phi \times 250 \mathrm{~mm}$, Waters Co., Tokyo, Japan $)$ with $60 \%$ $\mathrm{CH}_{3} \mathrm{CN} / 10 \mathrm{mM} \mathrm{NH}_{4} \mathrm{OAc}$ aq soln $(\mathrm{pH} 10)$ at $2.5 \mathrm{ml} \mathrm{min}^{-1}$ detected at UV $210 \mathrm{~nm}$. Each active fraction at the retention times of 22 and $26 \mathrm{~min}$ was concentrated in vacuo to dryness to afford leucinostatins B $(6.9 \mathrm{mg})$ and A $(9.8 \mathrm{mg})$ as white powders, respectively.

The ${ }^{1} \mathrm{H}$ NMR spectra of leucinostatins indicated $\alpha$-proton signals of amino acid residues at $\delta_{H} 4.0-5.5$ p.p.m. and singlet methyl signals of aminoisobutylic acid residues at $\delta_{H} 1.5-1.6$ p.p.m. The ${ }^{13} \mathrm{C}$ NMR spectra indicated $\alpha$-carbon signals of amino acid residues at $\delta_{C} 50-60$ p.p.m. and amide carbonyl carbons at $\delta_{\mathrm{C}} 175.5-189$ p.p.m. Leucinostatins $\mathrm{A}$ and $\mathrm{B}$ were identified by protonated ion peak $\left(\mathrm{m} / \mathrm{z},[\mathrm{M}+\mathrm{H}]^{+} 1218.6\right.$ ans 1024.6) and fragment ion peaks (A: $m / z$, 997.7, 784.6, 655.5, 631.1, 570.4, 546.0, 457,4, 435.3, 344.3, 259.2 and 222.2, B: $m / z, 983.5,770.3,641.1,556.3,546.2,443.0,329.9,222.0$ and 111.9) observed in electrospray ionization tandem mass spectrometry (ESI-MS) analysis, respectively.

\section{Trypanosomes}

Bloodstream forms of parasite used were T. $b$. brucei strain GUTat 3.1, T. $b$. rhodesiense strain STIB900 and T. $b$. brucei strain S427, as described earlier. ${ }^{6,7}$

\section{Animals}

Female CD1 mice (ICR), 20-25g, were obtained from Charles River Japan Inc. (Kanagawa, Japan). Animals were placed in groups of four per cage, kept in a room under negative pressure with flow of $0.1-0.2 \mathrm{~m} \mathrm{sec}^{-1}$. The animal room was held at a temperature of $25 \pm 2{ }^{\circ} \mathrm{C}$ and $60 \pm 10 \%$ relative humidity. Animals were maintained on a diet of CE-2 (Clea Japan Inc., Tokyo, Japan) and water ad libitum.

\section{In vitro assay}

In vitro antitrypanosomal activities for T. b. brucei strain GUTat 3.1 and T. $b$. rhodesiense strain STIB900 has been described earlier. ${ }^{6}$ In brief, $95 \mu \mathrm{l}$ of parasites suspension was incubated with $5 \mu \mathrm{l}$ of drug solution for $72 \mathrm{~h}$ and Alamar Blue was used for parasites survival determination to calculate $\mathrm{IC}_{50}$ values.

Cytotoxicity assay against MRC-5 cells was carried out as described earlier. ${ }^{11}$

\section{In vivo assay}

In vivo antitrypanosomal activities for T. b. brucei strain S427 and T. b. rhodesiense strain STIB900 were described earlier. ${ }^{7}$ In brief, female ICR mice were infected i.p. with parasites prepared from cryostabilate and drug treatment was carried out for 4 consecutive days. Efficacy of drug was determined by parasitaemia levels and the mean of survival days (MSD), compared with the untreated control group.

\section{RESULTS}

Table 1 shows in vitro antitrypanosomal activities of leucinostatin A and B, alamethicin I, tsushimycin and suramin. Leucinostatin A and B showed the most potent activity against both strains GUTat 3.1 and STIB900, with $\mathrm{IC}_{50}$ values ranging from $3.4-8.3 \mathrm{ng} \mathrm{ml}^{-1}$. Leucinostatins show approximately 200 -fold higher activity than suramin against the GUTat 3.1 strain. In the case of STIB900, they showed
12- to 15-fold higher values than suramin. Alamethicin I also showed potent impact against the GUTat 3.1 strain, with an $\mathrm{IC}_{50}$ value of $170 \mathrm{ng} \mathrm{ml}^{-1}$, some 9.3-fold lower value than suramin. Although tsushimycin showed the lowest IC $_{50}$ value of the three, it was still similar to that of suramin. The antitrypanosomal activity on strain STIB900 of both alamethicin I and tsushimycin was lower than that of suramin.

Evaluation of cytotoxicities of the peptides against MRC-5 cells is also shown in Table 1 . The $\mathrm{IC}_{50}$ values ranged between $2550->100000 \mathrm{ng} \mathrm{ml}^{-1}$. As a means to evaluate both antitrypanosomal activity and cytotoxicity, we introduced a selectivity index (SI), which is obtained by dividing $\mathrm{IC}_{50}$ of cytotoxicity by $\mathrm{IC}_{50}$ of antitrypanosomal activity. The SI of compounds tested is shown in Table 1. All three peptides had a higher SI than suramin in the case of strain GUTat 3.1/MRC-5, whereas in the case of STIB900 they were lower than suramin.

Table 2 shows in vivo antitrypanosomal activity, using the T. b. brucei S427 acute mouse model with leucinostatin A and B, alamethicin I, tsushimycin and suramin. Leucinostatin B showed curative effect at a dose of $1.0 \mathrm{mg} \mathrm{kg}^{-1} \times 4$, the same curative dosage as for suramin. Tsushimycin also showed a curative effect at a dose of $50 \mathrm{mg} \mathrm{kg}^{-1} \times 4$. Alamethicin I did not achieve cure at a dose of $3.0 \mathrm{mg} \mathrm{kg}^{-1} \times 4$, but extended the MSD, animals surviving approximately threefold longer than the untreated controls. Leucinostatin A and $\mathrm{B}$ did not show in vivo antitrypanosomal activity at a dose of $0.3 \mathrm{mg} \mathrm{kg}-1 \times 4$. The $\mathrm{LD}_{50}$ of leucinostatin $\mathrm{A}$ is reported to be $1.8 \mathrm{mg} \mathrm{kg}^{-1}$ i.p., ${ }^{12}$ therefore we tried $0.3 \mathrm{mg} \mathrm{kg}^{-1}$ i.p. $\times 4$ to try and avoid any toxic symptoms during treatment. Leucinostatin B showed toxicity at a dose of $2.5 \mathrm{mg} \mathrm{kg}^{-1} \times 2$ i.p.; however, treated mice withstood the toxicity and the infection was completely cured (data not shown). We also carried out in vivo evaluation using the T. b. rhodesiense strain STIB900 acute model with leucinostatin B (Table 3). Leucinostatin B showed 20\% cure activity, extending MSD by $>28$ days at the $1.0 \mathrm{mg} \mathrm{kg}^{-1} \times 4$ dosage. Suramin did not show curative activity, though it did cause extended MSD (by 25 days) using a dose of $1.0 \mathrm{mg} \mathrm{kg}^{-1} \times 4$. At the $10 \mathrm{mg} \mathrm{kg}^{-1} \times 4$ dosage level with suramin, a $50 \%$ curative rate was observed, with an extension of MSD by $>39.3$ days.

\section{DISCUSSION}

With regard to the commonly used therapeutic drugs, the mode of action of suramin and pentamidine remains unknown, whereas that of melarsoprol is poorly characterized. ${ }^{3}$

Table 1 In vitro antitrypanosomal activity and cytotoxicity of leucinostatin A and B, alamethicin I, tsushimycin and drugs used to treat Human African Trypanosomiasis

\begin{tabular}{|c|c|c|c|c|c|}
\hline \multirow[b]{3}{*}{ Compound } & \multicolumn{3}{|c|}{$I_{50}\left(\mathrm{ngm}^{-1}\right)$} & & \\
\hline & \multicolumn{2}{|c|}{ Antitrypanosomal activity } & \multirow{2}{*}{$\begin{array}{c}\text { Cytotoxicity } \\
\text { MRC-5 }\end{array}$} & \multicolumn{2}{|c|}{ Selectivity index (SI) } \\
\hline & GUTat 3.1 & STIB9O0 & & M/T.b.b. & M/T.b.r. \\
\hline Leucinostatin A & 7.8 & 3.4 & 2550 & 326.9 & 750.0 \\
\hline Leucinostatin B & 8.3 & 4.4 & 3110 & 374.7 & 706.8 \\
\hline Alamethicin I & 170 & 380 & 62500 & 367.6 & 164.5 \\
\hline Tsushimycin & 1090 & 2490 & $>100000$ & $>91.7$ & $>40.1$ \\
\hline Suramin & 1580 & 52 & $>100000$ & $>63$ & $>1923$ \\
\hline
\end{tabular}


Table 2 In vivo antitrypanosomal activity of leucinostatin A and B, alamethicin I, tsushimycin, pentamidine and suramin in $T$. b. brucei S427 mouse model

\begin{tabular}{|c|c|c|c|c|c|}
\hline Leucinostatin A & $0.3 \times 4$ & i.p. & $0 / 4$ & 5.5 & 5.5 \\
\hline Leucinostatin B & $1.0 \times 4$ & i.p. & $4 / 4$ & $>30$ & 5.5 \\
\hline Alamethicin I & $3.0 \times 4$ & i.p. & $0 / 4$ & 15 & 4.5 \\
\hline Tsushimycin & $50.0 \times 4$ & i.p. & $4 / 4$ & $>30$ & 4.4 \\
\hline Suramin & $1.0 \times 4$ & i.p. & $4 / 4$ & $>30$ & 5.5 \\
\hline
\end{tabular}

Table 3 In vivo antitrypanosomal activity of leucinostatin B, pentamidine and suramin in $T$. $b$. rhodesience STIB900 mouse model

\begin{tabular}{lcccc}
\hline Compound & Dosage $\left(\mathrm{mg} \mathrm{kg}^{-1}\right)$ & Route & No. of mice cured/no. of mice infected & Treated MSD \\
\hline Leucinostatin B & $1.0 \times 4$ & i.p. & $1 / 4$ & $>28$ \\
Suramin & $0.3 \times 4$ & i.p. & $0 / 4$ & 13 \\
& $10.0 \times 4$ & i.p. & $2 / 4$ & 11.3 \\
& $1.0 \times 4$ & i.p. & $0 / 4$ & 12.3 \\
\hline
\end{tabular}

Leucinostatins, ${ }^{13-15}$ alamethicin $\mathrm{I}^{16,17}$ and tsushimycin $^{18}$ are lipophilic peptide antibiotics produced as microbial metabolites. These antibiotics showed potent and moderately antitrypanosomal activity both in vitro and in vivo. Significantly, these three peptide antibiotics exhibited different characteristics compared with suramin with respect to sensitivity against strain GUTat 3.1 and strain STIB900. Consequently, the mode of action of the three might be different to that of suramin.

Leucinostatin acts on gram-positive bacteria, ${ }^{13,14}$ as an uncoupler in mitochondria, ${ }^{14,19-21}$ inhibitor of mitochondrial ATP synthesis, ${ }^{22}$ weak ionophore and immunosuppressant, ${ }^{23}$ blocker of virus glycoprotein expression $^{24}$ and as a nematicide. ${ }^{25}$

Although the bloodstream form of $T$. brucei has no oxidative phosphorylation, ${ }^{26}$ T. brucei mitochondrial ATP synthetase has been isolated and characterized. ${ }^{27}$ Brown et al. ${ }^{28}$ reported that ATP synthetase is responsible for the maintenance of membrane potential in blood-stream form trypanosomes, showing that RNAi knockdown of the $\alpha$ and $\beta$ subunits of the $F_{1}$ portion of ATP synthetase caused a slowdown in cell growth. It is therefore possible that leucinostatin A and B might be specific against T. brucei ATP synthetase.

Ishiguro et al. ${ }^{29}$ reported that leucinostatin might act on membrane phospholipids. When leucinostatin A acts as an ionophore, mono- $\left(\mathrm{H}^{+}\right.$and $\left.{ }^{86} \mathrm{Rb}^{+}\right)$and divalent $\left({ }^{45} \mathrm{Ca}^{2+}\right.$ and $\left.{ }^{65} \mathrm{Zn}^{2+}\right)$ cations were transported across both mouse thymocyte and artificial membrane and it increases intracellular calcium and decreases intracellular $\mathrm{pH}$ in the mouse thymocyte. ${ }^{23}$ T. brucei bloodstream-form parasites exposed to A-23187 (calcium ionophore) show gradual cell swelling, eventually forming a spherical appearance that was completed within $45 \mathrm{~min} .{ }^{30}$ Ruben et al. reported that intracellular calcium was increased approximately threefold by the addition of 4Br-A23187 (calcium ionophore) and intracellular calcium was superinduced with the proton ionophore FCCP, the $\mathrm{K}^{+} / \mathrm{H}^{+}$exchanger nigericin, and also intracellular $\mathrm{pH}$ was decreased. ${ }^{31}$ They also reported that amphiphilic peptide and amine caused $\mathrm{Ca}^{2+}$ influx across the plasma membrane, but did not disrupt membrane integrity. ${ }^{32}$

$\mathrm{Ca}^{2+}$ is a major signal transduction molecule in several organisms, including protozoan parasites. ${ }^{33}$ Acidocalcisomes are the main $\mathrm{Ca}^{2+}$ storage compartment in trypanosomatids and apicomplexan parasites, as well as an energy store for $\mathrm{Ca}^{2+}$ signaling and intracellular $\mathrm{pH}$ homeostasis. ${ }^{34}$ We had already found that leucinostatin A possesses antimalarial properties. ${ }^{35}$ There is thus an expectation that leucinostatins act as ionophores and disrupt parasite homeostasis resulting in antiparasite impact, but there might be an as yet unknown mode of action, including mitochondrial ATP synthesis inhibition, because leucinostatins show highly potent antiparasite activity both in vitro and in vivo.

Alamethicin I is reported to have mostly anti-gram-positive bacterial activity, ${ }^{36}$ act as an uncoupler of oxidative phosphorylation in rat mitochondria ${ }^{37}$ and possess hemolytic activity. ${ }^{38}$ The mode of action of alamethicin is considered to be through its effect on biomembrane systems by ion channel formation in lipid-membranes bilayers. ${ }^{17,39,40}$ It was reported that alamethicin seems to form ionic channels on chromaffin cells, which are permeable to $\mathrm{Ca}^{2+}, \mathrm{Mn}^{2+}$ and $\mathrm{Ni}^{2+} .41$ Dathe et al. ${ }^{42}$ reported that alamethicin induces catecholamine secretion from chromaffin cells and enhanced metabolic activity in endothelial cells. They showed that catecholamine secretion from bovine adrenal chromaffin cell was enhanced by alamethi cin dose-dependently in $\mathrm{Ca}^{2+}$-containing medium, whereas there was no effect using $\mathrm{Ca}^{2+}$-free medium. They suggested a peptidemediated $\mathrm{Ca}^{2+}$ entry into the cells. Alamethicin I might also act as an ionophore.

Tsushimycin, isolated from the culture broth of a Streptomyces strain, is related to the amphomycin-glumamycin group of antibiotics. ${ }^{18,43}$ The mode of action of tsushimycin is reportedly through inhibition of the formation of dolichyl phosphate mannose, dolichyl phosphate glucose and dolichyl pyrophosphate $\mathrm{N}$-acetylglucosamine, using particulate enzyme preparation from pig aorta. ${ }^{44}$ The related antibiotic, amphomycin, is reported to show in vivo antitrypanosomal activity against T. $b$. gambiense- and T. $b$. rhodesiense-infected mice. ${ }^{45}$ Furthermore, amphomycin showed inhibition of trypanosomal dolichol phosphate mannose synthase that gives mannose from dolichol phosphate mannose to synthesize the glycosylphosphatidylinositol anchor under the cell-free system. ${ }^{46}$ Tsushimycin may also inhibit T. brucei in the same manner as amphomycin. Study of the crystallized 
tsushimycin suggested that bioactive tsushimycin is most likely to involve $\mathrm{Ca}^{2+}$ ions that may interact with bacteria cell membranes at their fatty-acid side chain. ${ }^{43}$

The mode of action of the three antibiotics reported here is mainly expected to be via interaction with the membrane-lipid layer of trypanosomes.

It has been reported that antimicrobial peptides, such as defensins, cathelicidins $s^{47}$ and some cathelicidin families ${ }^{48}$ showed antitrypanosomal activity against both the bloodstream form and procyclic form of T. brucei. Especially, protegrin-1, a cathelicidin-class peptide showed in vivo survival elongation effect with daily treatment of $5 \mathrm{mg} \mathrm{kg}^{-1}$ i.p., treated parasites showing significant morphological change. ${ }^{47}$ The mode of action was described as disruption of cell wall/membrane integrity because of cationic and amphipathic characteristics. On the basis of cationic and amphipathic antibacterial peptides, GonzalezReyet et al. ${ }^{49}$ reported that vasoactive intestinal polypeptide and the structurally related pituitary adenylate cyclase-activating polypeptide have antitrypanosomal activity, specifically against the bloodstream form of parasites and that these peptides enter into and accumulate in the parasite cytosol.

Antimicrobial peptides have been classified into four groups on the basis of their structure ( $\beta$-sheet, $\alpha$-helical, extended and loop) and cationic and amphipathic characters. ${ }^{50}$ We showed that antitrypanosomal activity of the peptide antibiotics discussed have cationic and lipophilic character in the structure (Figure 1) and also these antibiotics have any of the $\beta$-sheet, $\alpha$-helical or loop conformations. ${ }^{17,43,51}$ Therefore, these peptides might act more selectively on $T$. brucei than mammalian cells, in spite of their toxicity. In the case of leucinostatin $\mathrm{A}$, it has been reported that leucinostatin A-loaded nanospheres show anti-Candida albicans activity both in vitro and in vivo, but with drastic reduction of toxicity. ${ }^{52}$

The above results reveal that leucinostatin A and B, alamethicin I and tsushimycin are promising lead compounds for a new type of antitrypanosomal activity. Further investigation of the antitrypanosomal potential of these peptide antibiotics is in progress.

\section{ACKNOWLEDGEMENTS}

This work was supported, in part, by funds from the Drugs for Neglected Diseases initiative (DNDi), and a grant for All Kitasato Project Study (AKPS). We are grateful to Dr Y Yabu, the Nagoya City University, Professor R Brun and Dr M Kaiser, the Swiss Tropical Institute, Professor T Kinoshita, the Research Institute for Microbial Diseases, Osaka University and Professor S Croft, Dr Eric Chatelain, Dr J-R Ioset, Dr C Brünger and Miss F Hirabayashi, DND $i$, for valuable discussions. We also thank Miss H Sekiguchi, Mr T Furusawa, Miss M Niitsuma and Miss J Hashida (Kitasato university) for her technical assistance throughout this work.

1 http://www.dndi.org/.

2 http://www. who.int/mediacentre/factsheets/fs259/en/.

3 Fairlamb, A. H. Chemotherapy of human African trypanosomiasis: current and future prospects. Trends Parasitol. 19, 488-494 (2003).

4 Matovu, E., Seebeck, T., Enyaru, J. C. K. \& Kaminsky, R. Drug resistance in Trypanosoma brucei spp., the causative agents of Sleeping Sickness in man and Nagana in cattle. Microbes Infect. 3, 763-770 (2001).

5 Brun, R., Schumacher, R., Schmid, C., Kunz, C. \& Burri, C. The phenomenon of treatment failures in Human African Trypanosomiasis. Trop. Med. Int. Health 6, 906-914 (2001).

6 Otoguro, K. et al. Selective and potent in vitro antitrypanosomal activities of 10 microbial metabolites. J. Antibiot. 61, 372-378 (2008).

7 Ishiyama, A. et al. In vitro and in vivo antitrypanosomal activities of two microbial metabolites, KS-505a and Alazopeptin. J. Antibiot. 61, 627-632 (2008).
8 Shaw, I. M. \& Taylor, A. The chemistry of peptides related to metabolites of Trichoderma spp. 2. An improved method of characterization of peptides of 2-methylalanine. Can. J. Chem. 64, 164-173 (1986).

9 von Arx, J. A. The genera of fungi sporulating in pure culture. 3rd edn., p. 263, J. Cramer. Vaduz. (1981).

10 Altschul, S. F., Gish, W., Miller, W., Myers, E. W. \& Lipman, D. J. Basic local alignment search tool. J. Mol. Biol. 215, 403-410 (1990).

11 Otoguro, K. et al. Potent antimalarial activities of the polyether antibiotic, X-206. J. Antibiot. 54, 658-663 (2001).

12 Mikami, Y. et al. Leucinostatins, peptide mycotoxins produced by Paecilomyces lilacinus and their possible roles in fungal infection. Zbl. Bakt. Hyg. 257, 275-283 (1984).

13 Arai, T., Mikami, Y., Fukushima, K., Utsumi, T. \& Yazawa, K. A new antibiotic, leucinostatin, derived from Penicillium lilacinum. J. Antibiot. 26, 157-161 (1973).

14 Fukushima, K. \& Arai, T. Studies on peptide antibiotics, leucinostatins I. Separation, physico-chemical properties and biological activities of leucinostatin A and B. J. Antibiot. 36, 1606-1612 (1983).

15 Fukushima, K. \& Arai, T. Studies on peptide antibiotics, leucinostatins II. The structures of leucinostatin A and B. J. Antibiot. 36, 1613-1630 (1983).

16 Pandey, R. C., Cook, Jr J. C. \& Rinehart, Jr K. L. High resolution and field desorption mass spectrometry studies and revised structures of alamethicins I and II. J. Am. Chem. Soc. 99, 8469-8483 (1977).

17 Leitgeb, B., Szekeres, A., Manczinger, L., Vágvölgyi, C. \& Kredics, L. The history of alamerhicin: a review of the most extensively studied peptaibol. Chem. Biodivers. 4, 1027-1051 (2007).

18 Shoji, J., Kozuki, S., Okamoto, S. \& Sakazaki, R. Studes on tsushimycin. I. Isolation and characterization of an acidic acylpeptide containing a new fatty acid. J. Antibiot. 21, 439-443 (1968).

19 Lardy, H., Reed, P. \& Lin, C. H. Antibiotic inhibitors of mitochondrial ATP synthesis. Fed. Proc. 34, 1707-1710 (1975).

20 Reed, P. W. \& Lardy, H. A. Uncoupling and specific inhibition of phosphoryl transfer reactions in mitochondria by the antibiotic A20668. J. Biol. Chem. 250, 3704-3708 (1975).

21 Mori, Y., Suzuki, M., Fukushima, K. \& Arai, T. Structure of leucinostatin B, an uncoupler on mitochondria. J. Antibiot. 36, 1084-1086 (1983).

22 Shima, A., Fukushima, K., Arai, T. \& Terada, H. Dual inhibitory effects of the peptide antibiotics leucinostatin in oxidative phosphorylation in mitochondria. Cell Struct. Funct. 15, 53-58 (1990).

23 Csermely, P. et al. The nonapeptide leucinostatin A acts as $\mathrm{s}$ weak ionophore and as an immunosuppressant on T lymphocytes. Biochim. Biophys. Acta. 1221, 125-132 (1994).

24 Muroi, M. et al. Novel blockade of cell surface expression of virus glycoprotein's by leucinostatin A. J. Antibot. 49, 119-1126 (1996).

25 Park, J. O. et al. Production of leucinostatins and nematicidal activity of Australian isolates of Paecilomyces lilacinus (Thom) Samson. Lett. Appl. Microbiol. 38, 271-276 (2004).

26 Kita, K., Nihei, C. \& Tomitsuka, E. Parasite mitochondria as drug target: diversity and dynamic change during the life cycle. Curr. Med. Chem. 23, 2535-2548 (2003).

27 Williams, N., Choi, S. Y., Ruyechan, W. T. \& Frank, P. H. The mitochondrial ATP synthase of Trypanosma brucei: Developmental regulation through the life cycle. Arch. Biochem. Biophys. 288, 509-515 (1991).

28 Brown, S. V., Hosking, O., Li, J. \& Wiliams, N. ATP synthase is responsible for maintaining mitochondrial membrane potential in bloodstream form Trypanosoma brucei. Eukaryotic Cell 5, 45-53 (2006).

29 Ishiguro, K. \& Arai, T. Action of the peptide antibiotic Leucinostatin. AAC 9, 893-898 (1976).

30 Bowles, D. J. \& Voorheis, H. P. Release of the surface coat from the plasma membrane of intact bloodstream forms of Trypanosoma brucei requires $\mathrm{Ca}^{2+}$. FEBS Lett. 139, 17-21 (1982).

31 Ruben, L., Hutchinson, A. \& Moehlman, J. Calcium homeostasis in Trypanosoma brucei. J. Biol. Chem. 266, 24351-24358 (1991).

32 Ruben, L., Akins, C. D., Haghighat, N. G. \& Xue, L. Calcium influx in Trypanosoma brucei can be induced by amphiphilic peptides and amines. Mol. Biochem. Parasitol. 81, 191-200 (1996).

33 Moreno, S. \& Docampo, R. Calcium regulation in protozoan parasites. Curr. Opin. Microbiol. 6, 359-364 (2003).

34 Docampo, R., Souza, W., Miranda, K., Rohloff, P. \& Moreno, S. Acidocalcisomesconserved from bacteria to man. Nat. Rev. Microbiol. 3, 251-261 (2005).

35 Otoguro, K. et al. In vitro antimalarial activities of microbial metabolites. J. Antibiot. 56, 322-324 (2003).

36 Meyer, P. \& Reusser, F. A polypeptide antibacterial agent isolated from Trichoderma viride. Experientica 23, 85-86 (1967).

37 Mathew, M. K., Nagaraj, R. \& Balaram, P. Alamethicin and synthetic peptide fragments as uncouplers of mitochondrial oxidative phosphorylation. Effect of chain length and charge. BBRC 98, 548-555 (1981).

38 Irmscher, G. \& Jung, G. The hemolytic properties of the membrane modifying peptide antibiotics, alamethicin, suzukacillin and trichotoxin. Eur. J. Biochem. 80, 165-174 (1977).

39 Mueller, P. \& Rudin, D. O. Action potentials induced in biomolecular lipid membranes. Nature 217, 713-719 (1968)

40 Woolley, G. A. Channel-forming activity of alamethicin: Effects of covalent tethering. Chem. Biodivers. 4, 1323-1337 (2007)

41 Fonteriz, R. I., López, M. G., Garcia-Sancho, J. \& Garca, A. G. Alamethicin channel permeation by $\mathrm{Ca}^{2+}, \mathrm{Mn}^{2+}$ and $\mathrm{Ni}^{2+}$ in bovine chromaffin cells. FEBS Lett. 283, 89-92 (1991). 
42 Dathe, M. et al. Proline at position 14 of alamethicin is essential for hemolytic activity, catecholamine secretion from chromaffin cells and enhanced metabolic activity in endothelial cells. Biochim. Biophys. Acta. 1370, 175-183 (1998).

43 Bunkóczi, G., Vértesy, L. \& Sheldric, G. M. Structure of the lipopeptide antibiotic tsushimycin. Acta. Crystallogr. D Biol. Crystallogr. 61, 1160-1164 (2005).

44 Elbein, A. D. The effect of tsushimycin on the synthesis of lipid-linked saccharides in aorta. Biochem. J. 193, 477-484 (1981).

45 Packchanian, A. Chemotherapy of African sleeping sickness. II. Chemotherapy of experimental Trypanosoma gambiense and Trypanosoma rhodesiense infections in mice (Mus musculus) with a new antibiotic, amphomycin. Antibiot. Chemother. 6, 684-691 (1956).

46 Menon, A. K., Mayor, S. \& Schwarz, R. T. Biosynthesis of glycosyl-phoshatidylinositol lipids in Trypanosoma brucei: involvement of mannosyl-phosphoryldolichol as the mannose donor. EMBO J. 9, 4249-4258 (1990).
47 McGwire, B. S., Olson, C. L., Tack, B. F. \& Engman, D. M. Killing of African trypanosomes by antimicrobial peptides. JID 188, 146-152 (2003).

48 Haines, L. R., Hancock, R. \& Pearson, T. W. Cationic antimicrobial peptides killing of African trypanosomes and Sodalis glossinidius, a bacterial symbiont of the insect vector of sleeping sickness. Vector Borne Zoonotic Dis. 3, 175-186 (2003).

49 Gonzalez-Rey, E., Chorny, A. \& Delgado, M. VIP: An agent with license to kill infective parasites. Ann. NY Acad. Sci. 1070, 303-308 (2006).

50 Powers, J. P. \& Hancock, R. The relationship between peptide structure and antibacterial activity. Peptides 24, 1681-1691 (2003).

51 Cerrini, S., Lamba, D., Scatturin, A. \& Ughetto, G. The crystal and molecular structure of the alpha-helical nonapeptide antibiotic leucinostatin A. Biopolymers 28, 409-420 (1989).

52 Ricci, M. et al. Leucinostatin-A loaded nanospheres: characterization and in vivo toxicity and efficacy evaluation. Int. J. Pharm. 275, 61-72 (2004). 